\title{
Exposure to Lead and Cadmium in the Sixth Total Diet Study - China, 2016-2019
}

\author{
Xin Zhao ${ }^{1}$; Yi Shao'; Lan $\mathrm{Ma}^{1, *}$; Xiaohong Shang ${ }^{1, *}$; Yunfeng Zhao'; Yongning $\mathrm{Wu}^{1}$
}

\section{Summary \\ What is already known about this topic \\ Lead $(\mathrm{Pb})$ and cadmium $(\mathrm{Cd})$ are widespread toxic heavy metal pollutants in the environment. Dietary intakes of $\mathrm{Pb}$ and $\mathrm{Cd}$ have been a major concern in the world. \\ What is added by this report? \\ The average dietary exposure to $\mathrm{Pb}$ and $\mathrm{Cd}$ among Chinese adult males from the Sixth China Total Diet Study (TDS) was within acceptable levels, except for a potential health risk of $\mathrm{Cd}$ exposure among adult men in Hunan Province. \\ What are the implications for public health practice? \\ It is necessary to continuously monitor the levels of $\mathrm{Pb}$ and $\mathrm{Cd}$ in foods. More attention should be paid to dietary Cd exposure in Hunan Province.}

Lead $(\mathrm{Pb})$ and cadmium $(\mathrm{Cd})$ are heavy metal pollutants that are widespread in the environment. $\mathrm{Pb}$ mainly damages nervous systems and particularly impacts children's cognitive ability and intelligence. $\mathrm{Cd}$ causes damage to multiple body systems and was identified as a human carcinogen by the International Agency for Research on Cancer (1). The dietary intakes of $\mathrm{Pb}$ and $\mathrm{Cd}$ have always been a major concern in the world.

Since 1990, China has conducted six Total Diet Studies (TDSs) to evaluate the dietary intake of various chemical substances and to assess the related health risks among Chinese population. The samples of this study were collected from the Sixth China TDS during 2016-2019. The dietary survey methods, sample collection, and processing methods are referenced in the Foreword of this special issue (2). The health risks of $\mathrm{Pb}$ intake were assessed using the margin of exposure (MOE) approach and that of $\mathrm{Cd}$ intake was assessed based on the provisional tolerable monthly intake (PTMI).

The levels of $\mathrm{Pb}$ and $\mathrm{Cd}$ in the food samples were determined by inductively coupled plasma mass spectrometry (ICP-MS). The limits of detection (LOD) of $\mathrm{Pb}$ and $\mathrm{Cd}$ determination were $0.08 \mu \mathrm{g} / \mathrm{kg}$ and $0.05 \mu \mathrm{g} / \mathrm{kg}$, respectively. Data below the LOD was processed using the methods recommended by the World Health Organization (WHO) (3).

The point estimate method was used to calculate the dietary intake of $\mathrm{Pb}$ and $\mathrm{Cd}$ and the contribution rate of various diets. In 2010, the provisional tolerable weekly intake (PTWI) value for $\mathrm{Pb}$ was withdrawn in the 73rd meeting of the Joint Food and Agriculture Organization of the United Nations (FAO)/WHO Expert Committee on Food Additives (JECFA). According to the evaluation results from JECFA, there is currently no health guidance threshold that can be established for $\mathrm{Pb}$. A margin of exposure (MOE) approach was initially recommended by the European Food Safety Authority (EFSA) to assess the risk caused by substances that were both genotoxic and carcinogenic. For adults, $\mathrm{Pb}$ exposure of $1.2 \mu \mathrm{g} / \mathrm{kg}$ body weight per day will lead to an increase of 1 $\mathrm{mmHg}$ in systolic blood pressure (4). In this study, the benchmark dose level $\left(\mathrm{BMDL}_{0.1}\right)$ of $1.2 \mu \mathrm{g} / \mathrm{kg}$ body weight per day was used for calculation. When the MOE value was greater than one, it indicated that the health risk of the current intake level was acceptable. In terms of $\mathrm{Cd}$, the PTWI value was replaced by PTMI value at the 73rd JECFA meeting because long-term $\mathrm{Cd}$ exposure poses a great threat to health and deserves more attention (5). Therefore, the health risk of dietary exposure to $\mathrm{Cd}$ was assessed based on the PTMI of $25 \mu \mathrm{g} / \mathrm{kg}$ body weight per month.

Of all composite samples from 24 provincial-level administrative divisions (PLADs) analyzed, 99.3\% had detectable residues of $\mathrm{Pb}$ and $88.9 \%$ had detectable residues of $\mathrm{Cd}$. Table 1 lists the national mean levels and ranges of $\mathrm{Pb}$ and $\mathrm{Cd}$ in 12 food categories. Foods with the highest mean $\mathrm{Pb}$ levels include vegetables $(15.7 \mu \mathrm{g} / \mathrm{kg})$, aquatic foods $(14.1 \mu \mathrm{g} / \mathrm{kg})$, legumes $(12.9 \mu \mathrm{g} / \mathrm{kg})$, cereals $(11.9 \mu \mathrm{g} / \mathrm{kg})$, and potatoes $(11.2 \mu \mathrm{g} / \mathrm{kg})$. Foods with the highest mean Cd levels include aquatic foods $(16.9 \mu \mathrm{g} / \mathrm{kg})$, legumes 
$(16.8 \mu \mathrm{g} / \mathrm{kg}), \quad$ cereals $(14.5 \mu \mathrm{g} / \mathrm{kg}), \quad$ vegetables $(12.5 \mu \mathrm{g} / \mathrm{kg})$, and potatoes $(11.1 \mu \mathrm{g} / \mathrm{kg})$.

The mean dietary $\mathrm{Pb}$ intake for Chinese adult male was $0.318 \mu \mathrm{g} / \mathrm{kg}$ body weight per day, ranging from $0.103 \mu \mathrm{g} / \mathrm{kg}$ body weight per day to $0.746 \mu \mathrm{g} / \mathrm{kg}$ body weight per day in 24 PLADs. The mean $\mathrm{Pb}$ intake in northern regions and southern regions were
$0.326 \mu \mathrm{g} / \mathrm{kg}$ body weight per day and $0.310 \mu \mathrm{g} / \mathrm{kg}$ body weight per day, respectively. Dietary intake of $\mathrm{Pb}$ from 12 food categories for adult males in 24 PLADs from the Sixth China TDS was shown in Figure 1. The top 3 dietary sources of $\mathrm{Pb}$ were cereals $(43.5 \%)$, vegetables $(29.0 \%)$, and beverages and water $(9.8 \%)$. The MOE value for the dietary exposure to $\mathrm{Pb}$ among

TABLE 1. The descriptive statistics of lead and cadmium from the Sixth China TDS, 2016-2019 $(\mu \mathrm{g} / \mathrm{kg})$.

\begin{tabular}{|c|c|c|c|c|c|c|c|c|}
\hline \multirow{2}{*}{ Food category } & \multicolumn{4}{|c|}{ Lead } & \multicolumn{4}{|c|}{ Cadmium } \\
\hline & Detection rate $(\%)$ & Mean & Min & Max & Detection rate $(\%)$ & Mean & Min & Max \\
\hline Cereals & 100 & $11.9 \pm 20.6$ & 1.2 & 47.6 & 100 & $14.5 \pm 33.5$ & 3.0 & 83.2 \\
\hline Legumes & 100 & $12.9 \pm 15.5$ & 4.7 & 34.9 & 100 & $16.8 \pm 18.5$ & 4.5 & 41.9 \\
\hline Potatoes & 100 & $11.2 \pm 16.2$ & 0.4 & 35.5 & 100 & $11.1 \pm 14.4$ & 2.3 & 30.8 \\
\hline Meats & 100 & $10.3 \pm 15.3$ & 1.3 & 28.9 & 100 & $2.4 \pm 3.7$ & 0.6 & 8.1 \\
\hline Eggs & 95.8 & $9.7 \pm 12.4$ & $<L O D$ & 25.3 & 100 & $1.1 \pm 4.0$ & 0.1 & 9.0 \\
\hline Aquatic foods & 100 & $14.1 \pm 19.4$ & 2.2 & 37.4 & 100 & $16.9 \pm 46.3$ & 0.9 & 83.8 \\
\hline Dairy products & 95.8 & $1.6 \pm 2.6$ & $<L O D$ & 4.8 & 50.0 & $0.1 \pm 0.5$ & $<$ LOD & 0.9 \\
\hline Vegetables & 100 & $15.7 \pm 24.4$ & 3.6 & 54.0 & 100 & $12.5 \pm 19.1$ & 2.9 & 46.6 \\
\hline Fruits & 100 & $5.0 \pm 8.6$ & 0.3 & 19.1 & 100 & $0.9 \pm 1.7$ & 0.3 & 4.3 \\
\hline Sugar & 100 & $9.7 \pm 30.4$ & 0.4 & 75.0 & 100 & $3.4 \pm 19.5$ & 0.1 & 49.0 \\
\hline Beverages \& water & 100 & $1.9 \pm 2.7$ & 0.2 & 5.7 & 50.0 & $0.1 \pm 0.4$ & $<L O D$ & 0.9 \\
\hline Alcohol & 100 & $1.9 \pm 3.4$ & 0.1 & 7.1 & 66.7 & $0.35 \pm 1.3$ & $<$ LOD & 2.9 \\
\hline
\end{tabular}

Note: When calculating the median/mean, the results below the LOD were set to $1 / 2$ LOD.

Abbreviations: TDS=total diet study; LOD=limit of detection.

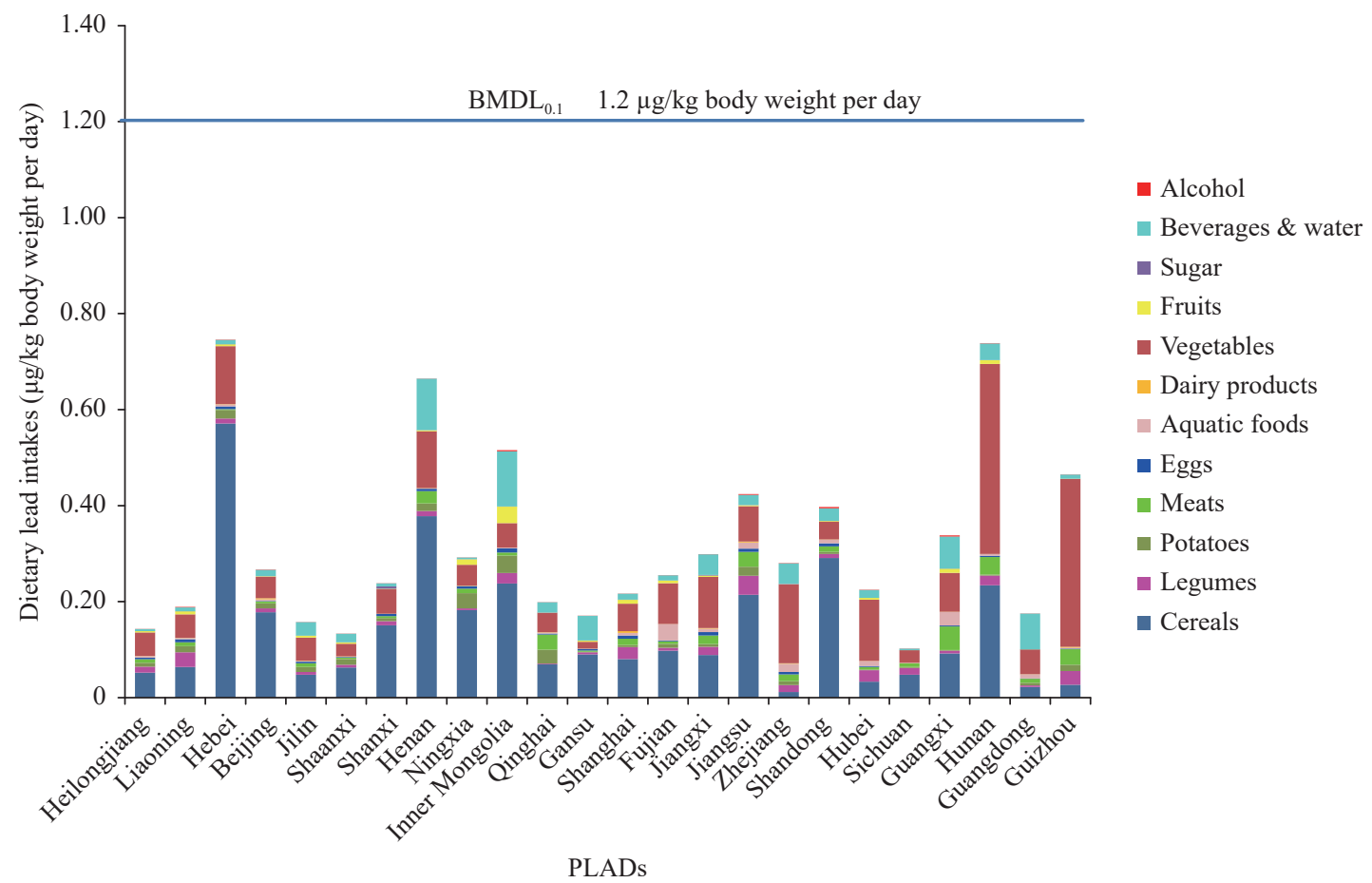

FIGURE 1. Dietary intake of lead for adult male in 24 PLADs from the Sixth China TDS, 2016-2019.

Abbreviations: BMDL=benchmark dose level; TDS=total diet study; PLADs=provincial-level administrative divisions. 


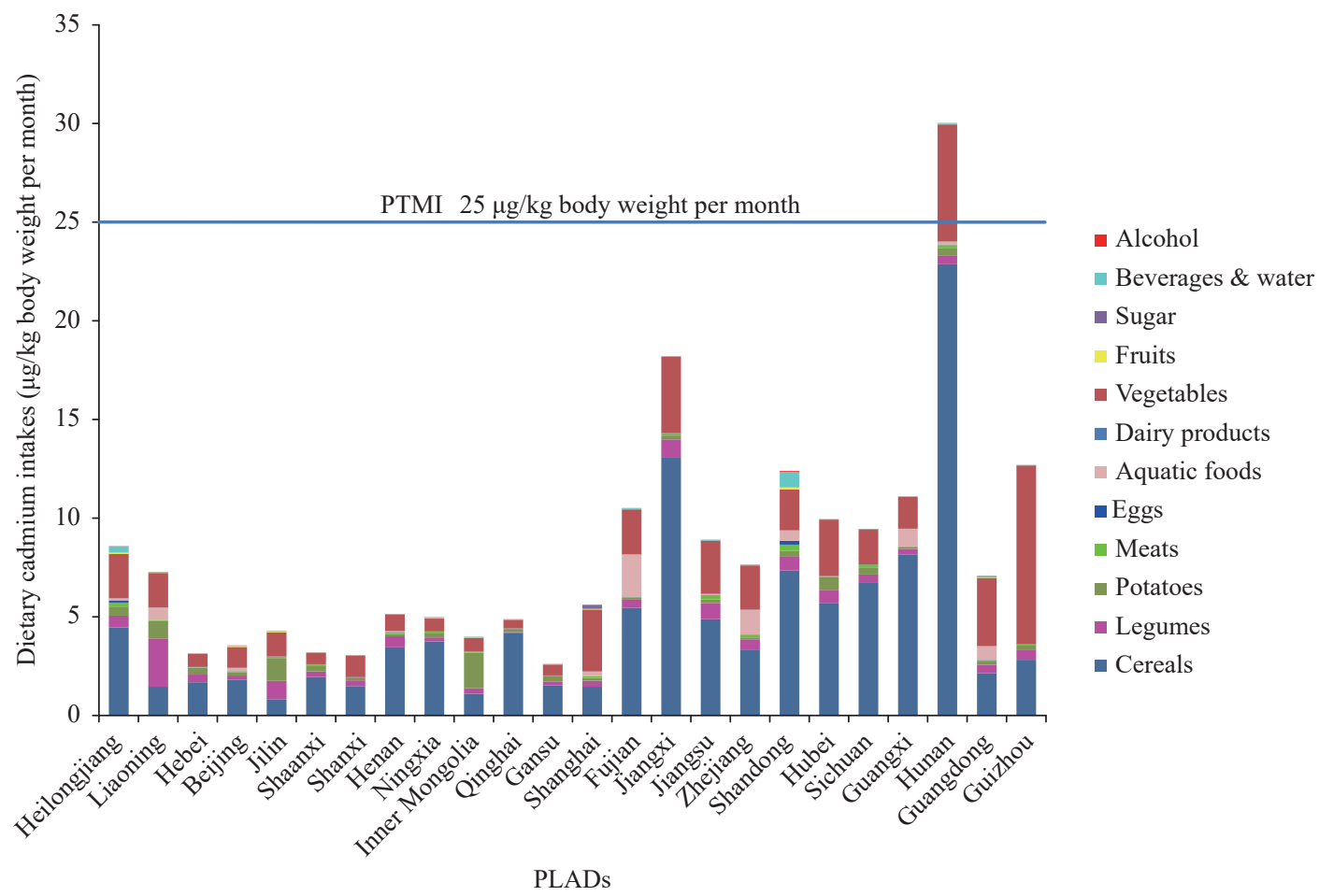

FIGURE 2. Dietary intake of cadmium for adult male in 24 PLADs from the Sixth China TDS, 2016-2019.

Abbreviations: PTMI=provisional tolerable monthly intake; TDS=Total Diet Study; PLADs=provincial-level administrative divisions.

adult male in 24 PLADs ranged from 1.6 to 11.7.

The mean $\mathrm{Cd}$ intake for Chinese adult males was $8.26 \mu \mathrm{g} / \mathrm{kg}$ body weight per month $(2.60-30.02 \mu \mathrm{g} / \mathrm{kg}$ body weight per month). The mean dietary Cd intakes in southern regions and northern regions were 11.96 $\mu \mathrm{g} / \mathrm{kg}$ body weight per month and $4.55 \mu \mathrm{g} / \mathrm{kg}$ body weight per month, respectively. Figure 2 showed the dietary intake of $\mathrm{Cd}$ from 12 food categories in 24 PLADs from the Sixth China TDS. The main contributors to $\mathrm{Cd}$ intake were cereals and vegetables (56.3\% and $26.6 \%$, respectively). The national mean intake of Cd was $33.0 \%$ of the PTMI, and the dietary intake of $\mathrm{Cd}$ in $24 \mathrm{PLADs}$ ranged between $10.4 \%$ and $120 \%$ of the PTMI. Only the Cd intake of adult males in Hunan Province (120\% PTMI) exceeded the PTMI.

\section{DISCUSSION}

The levels of $\mathrm{Pb}$ and $\mathrm{Cd}$ in all the dietary samples in Sixth China TDS were lower than the China General Standard for Contaminants in Foods (GB 2762-2017). The dietary $\mathrm{Pb}$ intake levels were similar in northern and southern regions, but the sources of dietary $\mathrm{Pb}$ intake were different. The contribution of cereals to lead intake in the southern region was similar to that of vegetables (31\% and $37.1 \%$, respectively). While in the northern region, the contribution of cereals $(50.6 \%)$ was higher than that of vegetables (19.7\%). Although $\mathrm{Pb}$ levels in beverages and water were low, but the consumption of beverages and water was large. As a result, the national mean contribution rate of beverages and water reached 9.8\%. The estimated MOE values were all above 1 for adult males of 24 PLADs, indicating that the risk of dietary exposure to $\mathrm{Pb}$ among Chinese adult male was at a safe level.

The dietary Cd intake was significantly higher in the southern region $(11.96 \mu \mathrm{g} / \mathrm{kg}$ body weight per month) than in the northern region $(4.55 \mu \mathrm{g} / \mathrm{kg}$ body weight per month). There were three possible reasons: 1) the mean Cd levels in many foods were higher in the south than that in the north; 2) the consumption of vegetables was significantly higher in the southern region than that in the northern region $(397.8 \mathrm{~g} / \mathrm{d} v \mathrm{~s}$. $297.3 \mathrm{~g} / \mathrm{d}$ ) and vegetables were one of the main sources of Cd intake; or 3) southern and northern regions had different dietary habits. Rice is the main staple food in the south while wheat flour is the main staple food in the north, and rice had higher levels of $\mathrm{Cd}$ than flour. 
For adult males from Hunan Province, cereals contributed up to $76 \%$ of the dietary $\mathrm{Cd}$ intake. Cereals from Hunan Province contained the highest Cd level among all cereals from the 24 PLADs (83.17 $\mu \mathrm{g} / \mathrm{kg}$; 5.8 times the national mean cereal Cd level of $14.45 \mu \mathrm{g} / \mathrm{kg}$ ), which could be a potential health risk to adult males in that region.

Since 1990, China has conducted 6 China TDSs $(6-10)$. Supplementary Figure S1 (available in https://weekly.chinacdc.cn/) shows that dietary $\mathrm{Pb}$ intake remained relatively stable during the first three TDSs, and gradually decreased during the latter three TDSs. The dietary $\mathrm{Cd}$ intake presented a slight increasing trend from the First TDS to the Fifth TDS, while a significant decrease of $47 \%$ (compared with the Fifth TDS) was observed in the Sixth TDS. This was likely due to China's efforts in controlling environmental pollution during recent years. However, compared to other countries (Supplementary Table S1, available in https://weekly.chinacdc.cn/), $\mathrm{Pb}$ and $\mathrm{Cd}$ intakes remained at relatively high levels, which was concerning.

There were some limitations in this study. The current exposure assessment was conducted based on the consumption pattern of Chinese adults and did not involve that of infants and young children.

The present study revealed that the risks of dietary exposure to $\mathrm{Pb}$ and $\mathrm{Cd}$ among Chinese adult male were generally low, except for the risk of $\mathrm{Cd}$ exposure in Hunan Province. Since it is difficult to establish a safety threshold for $\mathrm{Pb}$, JECFA recommended that countries should try to reduce $\mathrm{Pb}$ intake to as little as possible. It is necessary to continuously monitor the levels of $\mathrm{Pb}$ and $\mathrm{Cd}$ in foods to ensure the food safety and health of Chinese population.

Acknowledgements: The 24 provincial-level CDCs.

Conflicts of interest: The authors declare that there are no conflicts of interest.

Funding: This research was supported by the National Key Research and Development Program of China (grant number 2017YFC1600500), and CAMS
Innovation Fund for Medical Science (CIFMS 2019I2M-5-024).

doi: $10.46234 /$ ccdcw2022.045

\# Corresponding authors: Lan Ma, malan@cfsa.net.cn; Xiaohong Shang, shangxh@cfsa.net.cn.

1 NHC Key Laboratory of Food Safety Risk Assessment, China National Center for Food Safety Risk Assessment, Beijing, China.

Submitted: November 29, 2021; Accepted: February 28, 2022

\section{REFERENCES}

1. Zhu BC, Wang YL, Guo BF, Zhao SQ, Li XC. Risk assessment of cadmium dietary exposure among residents in Nanjing, 2013-2016. Pract Prev Med 2019;26(9):1027 - 30. http://dx.doi.org/10.3969/j. issn.1006-3110.2019.09.002.

2. Lyu B, Li JG, Wu YN. Characterizing exposome of food contamination and China Total Diet Study: project for improving food safety risk assessment in China. China CDC Wkly 2022;4(9):157 - 60. http://dx. doi.org/10.46234/ccdcw2022.039.

3. WHO. Chapter 6: dietary exposure assessment of chemicals in food. In: WHO, editor. Principles and methods for the risk assessment of chemicals in food. Geneva: World Health Organization. 2009; 1-61. https://www.who.int/foodsafety/chem/dietary_exposure.pdf.

4. World Health Organization (WHO). Safety evaluation of certain food additives and contaminants. Geneva: World Health Organization; 2011; p. 381-497. WHO food Additives Series: 64. https://apps.who. int/iris/bitstream/handle/10665/44521/9789241660648_eng.pdf; sequence $=1$.

5. World Health Organization (WHO). Safety evaluation of certain food additives and contaminants. Geneva: World Health Organization; 2011; p. 372-374. WHO food Additives Series: 64. https://apps.who. int/iris/bitstream/handle/10665/44521/9789241660648_eng. pdf;sequence $=1$.

6. Chen JS, Gao JQ. The Chinese Total Diet Study in 1990. Part I. Chemical Contaminants. J AOAC INT 1993;76(6):1193-205.

7. Chen JS, Gao JQ. The Chinese Total Diet Study in 1992-chemical contaminants (I) comparison between different areas. J Hygiene Res 1997;26(3):199 - 203. http://dx.doi.org/10.19813/j.cnki.weisheng yanjiu.1997.03.016. (In Chinese).

8. Gao JQ, Li XW, Zhao JL. 2000 Chinese Total Diet Study-the dietary lead and cadmium intakes. J Hygiene Res 2006;35(6):750-4. http:// kns.cnki.net $/ \mathrm{kcms} /$ detail/detail.aspx?dbcode=CJFD\&dbname=CJFD2006 \&filename=WSYJ200606025\&uniplatform $=$ NZKPT \&v=rXa2bRDGg PjMwxBTIYX_wWPU4Lcxlr8tmY5xMD9eHukEyT9HyclYiuq0tz2mie QB. (In Chinese).

9. Wu YN, Li XW. The fourth China Total Diet Study. Beijing: Chemical Industry Press. 2015. http://www.bookschina.com/7008102.htm. (In Chinese).

10. Wu YN, Zhao YF, Li JG. The fifth China Total Diet Study. Beijing: Science Press. 2018. http://www.zxhsd.com $/ \mathrm{kgsm} / \mathrm{ts} / 2018 / 09 / 03 /$ 4250027.shtml. (In Chinese). 


\section{SUPPLEMENTARY MATERIALS}

SUPPLEMENTARY TABLE S1. Comparison of dietary intake of lead and cadmium with other countries.

\begin{tabular}{|c|c|c|c|c|}
\hline Country & $\begin{array}{c}\text { Mean dietary lead intake } \\
(\mu \mathrm{g} / \mathrm{kg} \text { body weight per day) }\end{array}$ & Mean dietary cadmium intake (unit) & Population & Reference \\
\hline French & 0.2 & $0.16(\mu \mathrm{g} / \mathrm{kg}$ body weight per day) & adult & 1 \\
\hline USA & $0.047-0.28$ & $0.2(\mu \mathrm{g} / \mathrm{kg}$ body weight per day) & whole population & 2 \\
\hline U.K. & $0.09-0.10$ & $\begin{array}{c}0.14-0.17(\mu \mathrm{g} / \mathrm{kg} \text { body weight per } \\
\text { day) }\end{array}$ & adult & 3 \\
\hline Australia & $0.018-0.16$ & $\begin{array}{c}2.0-5.5(\mu \mathrm{g} / \mathrm{kg} \text { body weight per } \\
\text { month) }\end{array}$ & $\begin{array}{l}19 \text { years and } \\
\text { above }\end{array}$ & 4 \\
\hline Canada & 0.13 & $0.2(\mu \mathrm{g} / \mathrm{kg}$ body weight per day) & $40-64$ years male & 5 \\
\hline China & 0.316 & $8.3(\mu \mathrm{g} / \mathrm{kg}$ body weight per month) & adult & $\begin{array}{l}\text { The present } \\
\text { study }\end{array}$ \\
\hline
\end{tabular}

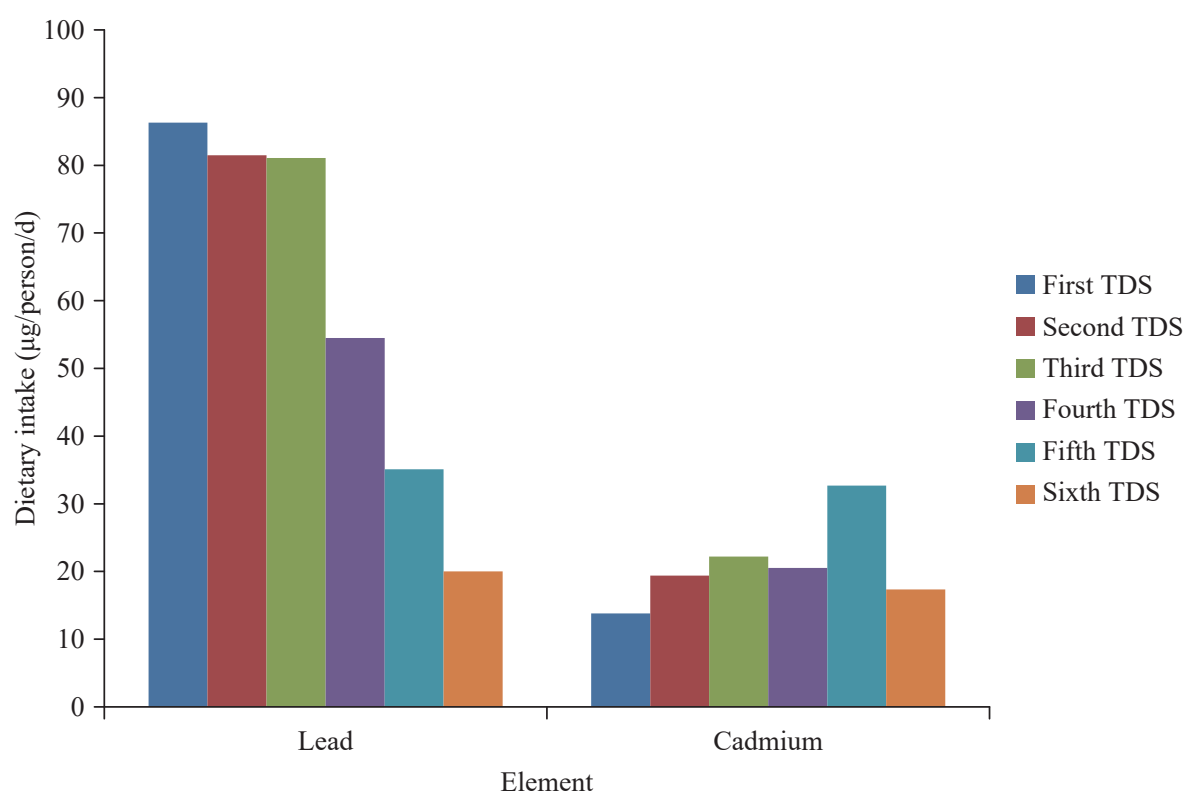

SUPPLEMENTARY FIGURE S1. Comparison of lead and cadmium intakes from the First China Total Diet Study (TDS) to the Sixth China TDS (Data source: First China TDS (6), Second China TDS (7), Third China TDS (8), Fourth China TDS (9), and Fifth China TDS (10)) .

Note: The dietary intake in the figure refers to the daily intake for an adult man weighing $63 \mathrm{~kg}$.

\section{REFERENCES}

1. Arnich N, Sirot V, Rivière G, Jean J, Nöel L, Guérin T, et al. Dietary exposure to trace elements and health risk assessment in the 2nd French Total Diet Study. Food Chem Toxicol 2012;50(7):2432 - 49. http://dx.doi.org/10.1016/j.fct.2012.04.016.

2. Egan SK, Tao SSH, Pennington JAT, Bolger PM. US Food and Drug Administration's Total Diet Study: intake of nutritional and toxic elements, 1991-96. Food Addit Contam 2002;19(2):103 - 25. http://dx.doi.org/10.1080/02652030110071354.

3. Rose M, Baxter M, Brereton N, Baskaran C. Dietary exposure to metals and other elements in the 2006 UK total diet study and some trends over the last 30 years. Food Addit Contam Part A Chem Anal Control Expo Risk Assess 2010;27(10):1380 - 404. http://dx.doi.org/10.1080/19440049.2010. 496794.

4. FSANZ. 25th Australian total diet study. Canberra: Food Standards Australia New Zealand. https://www.foodstandards.gov.au/publications/Documents/ 25thAustralianTotalDietStudy.pdf

5. Health Canada. Canadian total diet study. Dietary intakes of contaminants and other chemicals for different age-sex groups of Canadians. http://www.hcsc.gc.ca/fn-an/surveill/total-diet/intake-apport/chem_age-sex_chim_2007-eng.php

6. Chen JS, Gao JQ. The Chinese Total Diet Study in 1990.Part I.Chemical Contaminants. J AOAC INT.1993;76(6)1193-1205.Chen JS, Gao JQ. The Chinese total diet study in 1992-chemical contaminants (I) comparison between different areas. J Hygiene Res 1997;26(3):199 - 203. http://dx.doi.org/ 10.19813/j.cnki.weishengyanjiu.1997.03.016. (In Chinese).

7. Gao JQ, Li XW, Zhao JL. 2000 Chinese total diet study-the dietary lead and cadmium intakes. J Hygiene Res 2006;35(6):750-4. http://kns. cnki.net $/ \mathrm{kcms} /$ detail/detail.aspx?dbcode=CJFD\&dbname=CJFD2006\&filename=WSYJ200606025\&uniplatform $=\mathrm{NZKPT \& v=rXa2bRDGgPjMwxB}$ TIYX_wWPU4Lcxlr8tmY5xMD9eHukEyT9HyclYiuq0tz2mieQB. (In Chinese).

8. Wu YN, Li XW. The fourth China total diet study. Beijing: Chemical Industry Press. 2015. (In Chinese).

9. Wu YN, Zhao YF, Li JG. The fifth China total diet study. Beijing: Science Press. 2018. (In Chinese). 